\title{
COMPETÊNCIA TRADUTÓRIA, LÍNGUAS PRÓXIMAS, INTERFERÊNCIA: EFEITOS HIPNÓTICOS EM TRADUÇÃO DIRETA
}

\begin{abstract}
Heloisa Pezza Cintrão*
RESUMO: O par lingüístico específico pode ter impacto sobre a interação entre as subcompetências da competência tradutória (PACTE: 2001). Tendo isso em vista, discutiremos como o trabalho com o par português-espanhol pode repercutir sobre a competência tradutória e seu desenvolvimento, focando especialmente o fenômeno da interferência em tradução. O cruzamento de dados de estudos sobre o grau de proximidade entre o português e o espanhol nos levará a propor que se trata de um par de línguas medianamente próximas. Explicações da interferência em aquisição de língua estrangeira, em relação com a distância-proximidade de um par lingüístico, fornecerão parâmetros para analisar a interferência em tradução e sua especificidade no par português-espanhol.
\end{abstract}

UNITERMOS: interferência; linguas próximas; tradução direta; competência tradutória.

ABSTRACT: The specific linguistic pair can intervene on the interaction between the subcompetences of translation competence (PACTE: 2001). Considering this, we will discuss how the work with the Portuguese-Spanish pair can impact on the translation competence and on its development, focusing on the phenomenon of interference in translation. Crossing data of some studies on the degree of proximity between Portuguese and Spanish suggests that these languages are moderately similar. Explanations of the interference in foreign language acquisition, relating with the distance-proximity of a linguistic pair, will establish parameters

* Universidade de São Paulo, Brasil. 
to examine the interference in translation and its peculiarity in the Portuguese-Spanish pair.

KEYWORDS: interference; near languages; direct translation; translation competence.

\section{Introdução}

O aprendiz de uma língua estrangeira e o tradutor têm em comum o contato entre duas línguas em sua mente. Para um tradutor típico, uma delas é sua língua materna (LM) e a outra, uma lingua estrangeira adquirida posteriormente (L2). Entre diferentes pares de linguas pode haver graus bastante variáveis de proximidade/distância.

No caso da aquisição de uma L2 e no caso da tradução interlingüística, é importante perguntar-se sobre os efeitos que pode ter a peculiar relação de distâncias e proximidades entre o par de linguas envolvido (LM-L2) e os mecanismos que são ativados cognitivamente quando as duas línguas interagem.

Tanto na aquisição/aprendizagem ${ }^{1}$ de L2 quanto no caso da tradução, ao se tratar da interação entre duas línguas no ambiente cognitivo, a transferência negativa ou interferência recebe destaque como um fenômeno que leva a resultados indesejáveis no desempenho do aprendiz de uma língua estrangeira ou no produto de uma tradução.

Partindo dessas considerações, abordaremos: (i) a interferência no quadro da aquisição de L2 em sua relação com a distância/proximidade do par lingüístico; (ii) parâmetros para avaliar as relações de distância ou proximidade entre o português e o espanhol; (iii) aspectos da interferência na tradução direta escrita e da especificidade do trabalho com o par português-espanhol, na condição de línguas próximas, na tradução direta escrita.

1 Usaremos "aquisição" e "aprendizagem" como sinônimos neste artigo. 


\section{Interferência: definição e primeira hipótese explicativa}

\subsection{A interferência na aquisição de L2}

Definiremos inicialmente "interferência" como a incorporação de elementos de uma língua na produção em outra. ${ }^{2}$ No caso da aquisição de L2, elementos da LM de um aprendiz aparecem em sua produção na L2. A noção de "interferência" ou "transferência" é abordada nos estudos de aquisição de L2 e daí passa aos Estudos de Tradução.

Segundo hipóteses behavioristas sobre a aprendizagem, a interação entre LM e L2 na aquisição de L2 dar-se-ia de maneira a facilitar a aprendizagem da L2 naquelas regiões em que o par lingüístico LM e L2 apresentasse semelhanças, ao passo que onde houvesse diferenças haveria dificuldade de aprendizagem e se concentraria a maior parte dos erros dos aprendizes. Daí a proposta de estratégias de ensino de L2 baseadas em estudos contrastivos detalhados: seria desejável arrolar exaustivamente as diferenças entre LM e L2 e dirigir o trabalho pedagógico especialmente sobre essas diferenças. Essa visão enfrenta objeções, principalmente a de fundamentar-se numa concepção taxonomista da aquisição de L2 como um processo linear de progressivo acúmulo mecânico de um repertório de palavras e estruturas.

Num importante trabalho sobre o papel da LM na aquisição de L2, Corder (1983) manifesta desacordo com a visão behaviorista das relações entre LM e L2 na aquisição de L2, considerando haver várias evidências empíricas de sua inadequação. Esse autor rejeita o conceito de "interferência", por seus vínculos com visões behavioristas e taxonomistas de aquisição de L2, e recomenda cuidado no uso da palavra "transferência".

Para Corder (1983: 87), o processo de aquisição consistiria na criação de um corpo de conhecimentos implícitos sobre o qual o aprendiz constrói seus enunciados na L2. Adquirir uma língua é considerado um processo criativo no qual os aprendi-

2 Mackey (1970) apud Presas (2000: 25). 
zes, em interação com o meio, vão construindo uma representação internalizada (holística e complexa) das regularidades percebidas nos dados lingüísticos a que são expostos. Este processo seria dinâmico, já que os aprendizes passam por fases continuadas de aprendizagem, com a chamada "interlingua" se refazendo e se reestruturando constante e sistemicamente no contato com material lingüístico novo (input) que reforce ou desestabilize hipóteses já construídas (e inter-relacionadas) sobre o funcionamento da L2.

Sobre o papel da LM nesse processo, Corder aponta que "há uma relação clara entre a velocidade da aquisição e a chamada distância lingüística" (p. 88), de modo que quanto mais parecidas a LM e a L2 aprendida, maior a ajuda que a LM poderia dar na aquisição da L2; e, quanto menos parecidas, menor essa ajuda. Assim, entre línguas próximas, o processo de aquisição costuma ser mais acelerado.

O papel da LM na aprendizagem de uma L2 seria então um papel heurístico e facilitador: auxiliaria no processo de descoberta e criação de representações da nova língua. No caso de linguas distantes, não teríamos "interferência" como inibição da LM sobre o processo de aquisição, mas apenas ausência ou falha do componente facilitador.

O fenômeno do "empréstimo" explicaria a "interferência", quando entendida como o aparecimento, na produção em L2, de características da LM. Corder define o empréstimo como um fenômeno próprio do desempenho, uma estratégia comunicativa caracterizada pelo uso temporário ou permanente de um elemento de uma língua na produção em outra, e sustenta que não seria apropriado falar de interferência ou transferência neste caso, pois o falante simplesmente usa sua LM para expressar certo estado de coisas por não ter, em sua interlíngua, meios para fazê-lo, e "assim como não dizemos que uma pessoa está transferindo nada quando usa sua língua materna em outro contexto", também não deveríamos fazê-lo neste caso. Em situações em que uma pressão comunicativa excede o conhecimento, o empréstimo aparece mais acentuadamente. É uma estratégia que perde força à medida que se conhece melhor a L2, aponta Corder. 
A freqüência do recurso ao empréstimo como estratégia comunicativa é uma função da percepção que o falante tem da relação de proximidade entre LM e L2. Quando a distância lingüística é grande, os falantes tendem a descobrir a impossibilidade de valer-se de empréstimos, daí sua menor incidência neste caso e a conseqüente menor incidência de erros devidos a empréstimos inadequados. Quando as línguas são próximas, as tentativas de empréstimo são relativamente mais bem-sucedidas.

A estratégia do empréstimo pode conduzir tanto à produção de enunciados incorretos quanto de enunciados corretos. Se tiverem sucesso comunicativo, tanto formas diferentes (incorretas) quanto similares (corretas) podem ser incorporadas à interlíngua.

O impulso do aprendiz de recorrer ao empréstimo é acentuado ou inibido de acordo com sua percepção da menor ou maior distância entre sua LM e a L2. Assim, a proximidade lingüística apresenta duas faces interconectadas na aquisição / aprendizagem: facilitação e transferência. Por fim, o raciocínio leva a supor que linguas medianamente próximas teriam potencializadas as probabilidades de interferência, ou seja, que precisamente onde as línguas são apenas moderadamente similares teríamos potencialmente as maiores incidências de erros devidos ao empréstimo.

Uma importante diferença que o fenômeno da interferência apresenta entre sua manifestação no campo da aquisição de L2 e no campo da tradução direta (da L2 para a LM) é acontecer, aparentemente, em direções diferentes. No caso de um aprendiz falando ou escrevendo na L2, o sentido da interferência se verifica da LM para a L2. No caso de uma tarefa de tradução direta escrita, acontece na direção oposta (L2 $\rightarrow$ LM). O empréstimo, suposto motor do fenômeno da transferência no caso da aquisição de L2 (sentido LM $\rightarrow$ L2), poderia explicar também o fenômeno da transferência na tradução direta escrita, que parece se dar na direção inversa? Por que um falante que está se expressando em sua LM tomaria emprestados elementos da L2, quando a LM é a língua em que tem repertório lingüístico mais amplo, de modo que supostamente não teria menos elementos para expressar-se nela a ponto de precisar lançar mão de empréstimos da L2? 


\subsection{Línguas próximas: facilitação e interferência na compreensão leitora}

Como vimos em 2.1, ao explicar a transferência e a facilitação na aquisição como conseqüências da estratégia do empréstimo, Corder parece focar especialmente as habilidades de produção na L2, mas seria igualmente possivel, no caso das habilidades receptivas, pensar no empréstimo operando no quadro de um uso heurístico da LM para aproximar-se da compreensão da L2, com suas duas conseqüências: sucesso-facilitação e insucesso-interferência. Ao processar interpretativamente um enunciado numa L2, semelhanças com a LM podem levar a que o conhecimento da LM seja transferido para o processo de compreensão da L2. Quando à semelhança no plano dos significantes corresponder uma semelhança no plano dos sentidos, a LM facilitará a compreensão. Caso contrário, semelhanças apenas aparentes poderão levar à interferência na forma de equívoco de interpretação (Durão: 2000).

Isso posto, entenderemos por "interferência" ${ }^{3}$ o uso de elementos de uma língua (1) ao expressar-se em outra ou (2) ao processar interpretativamente uma outra. Ampliamos, assim, a definição apresentada nas páginas iniciais, de modo a englobar explicitamente a interferência nas habilidades de compreensão, e não apenas nas de produção.

Seguindo a Ringbon (1992: 88-89), Durão (2002: 14) propõe dois aspectos da proximidade lingüística facilitadora da compreensão leitora:

1) Similitude lexical. Um grande número de homógrafos unissêmicos (cognatos comuns) entre LM e L2 é um aspecto facilitador da compreensão leitora na L2. Ringbon entende que os cognatos da L2 não são propriamente "aprendidos":

\footnotetext{
3 Sem a intenção de vincular-nos a uma visão behaviorista e taxonomista do papel da LM na aquisição da L2, usaremos a palavra "interferência", por ser esse o termo que temos encontrado para designar o fenômeno em questão em trabalhos no âmbito nos Estudos de Tradução, e eventualmente usaremos "transferência" como sinônimo, cientes das diferentes vinculações de cada um dos termos nos Estudos de Aquisição.
}

TradTerm, 12, 2006, p. 69-104 
pertencem ao vocabulário potencial do aprendiz proporcionado quase de maneira direta pela LM.

2) Similitude estrutural. Havendo similitude entre os sistemas gramaticais da LM e da L2, o aprendiz compreende com menos esforço o funcionamento morfossintático da L2. Esse é outro fator facilitador na tentativa de interpretar o que se lê. Nesse caso, o sentido geral das mensagens pode ser suficiente para que o aprendiz entenda um texto na L2, mesmo desconhecendo algumas palavras ou quando encontre falsos cognatos.

Estes dois aspectos seriam facilitadores do entendimento e do uso de uma L2 mesmo antes da exposição a uma aprendizagem formal.

Segundo Durão, considerando a facilitação que a proximidade lingüística pode significar, o português como LM parece funcionar como uma base transferivel bastante rentável para o uso do espanhol como L2, muito especialmente, no caso da compreensão leitora, principal habilidade requerida na L2, no caso da tradução direta escrita.

Por outro lado, a autora aponta que não se pode eludir o fato de que "há formas e estruturas lingüísticas que parecem transparentes, mas que na realidade são opacas, podendo, portanto, perturbar o processo leitor apesar do contexto" (p. 14).

Tendo em mente que a interferência está em estreita relação com graus de proximidade lingüística, a seguir procuraremos parâmetros para estimar o grau de proximidade entre o português e o espanhol, examinaremos essa proximidade do ponto de vista de diferentes estratos lingüísticos e consideraremos efeitos que o jogo de distâncias e proximidades entre esse par lingüístico pode ter do ponto de vista da tradução. 


\section{Parâmetros para as proximidades e distâncias entre o português e o espanhol}

\subsection{Similitude lexical: problemas de uma visão dicotômica}

Como exemplo de uma tentativa de quantificar a proximidade lexical entre o português e o espanhol, interessa-nos o estudo de Richman (1965), descrito por Durão. Naquele estudo, examinou-se um corpus de milhares de palavras e concluiu-se que $90 \%$ das palavras analisadas eram cognatos homossemânticos; $60 \%$ eram cognatos idênticos; $35 \%$ poderiam ser facilmente reconhecidas por meio de uma inclusão, exclusão, substituição ou deslocamento de uma ou outra letra dentro da palavra. Também apontava-se uma importante coincidência na ordem canônica das orações, dentro do padrão SVO, e destacadas semelhanças nas estruturas sintáticas.

A respeito do estudo de Richman, Durão (2002: 16) pontua que, embora a origem etimológica comum de grande parte do acervo léxico do português e do espanhol seja um facilitador importante para o conhecimento intuitivo do significado de uma boa quantidade de palavras, por vezes originou similitudes limitadas ao plano do significante, devido a diferentes desenvolvimentos históricos entre ambas as línguas.

Vale ilustrar essas considerações com alguns exemplos de supostos cognatos.

1) Diferentes freqüências de uso entre pares de sinônimos nos dois idiomas. Nos pares de sinônimos enfermedad- "enfermidade" / dolencia - "doença", ${ }^{4}$ a relação entre a freqüência com que português brasileiro (PB) e espanhol selecionam um ou outro dos sinônimos pertencentes ao sistema lexical é inversa. Um brasileiro seleciona com freqüência acentuadamente maior para o registro coloquial a palavra "doença", enquanto que um falante do espanhol selecionaria para si-

\footnotetext{
4 Durante todo este artigo, exemplos de palavras, sintagmas e enuncia-
} dos do espanhol aparecerão em itálico, e os do português, "entre aspas".

TradTerm, 12, 2006, p. 69-104 
tuações de uso equiparáveis a palavra enfermedad. Usando a Internet como corpus, é possivel encontrar dados de freqüência que demonstram que essa percepção intuitiva para um bilíngüe proficiente nas duas línguas é verificável estatisticamente em corpora. Exemplos como esse se repetem abundantemente entre o português e o espanhol.

A percepção da freqüência de uso em diferentes domínios discursivos, registros ou mesmo dialetos entre um par de sinônimos intralingüísticos requer um domínio amplo e refinado dos sistemas lexicais e das relações desses sistemas com fatores pragmáticos e discursivos que interferem nos efeitos de sentido de um enunciado ou texto, e isso tem evidentes implicações para pensar o que significa compreender para traduzir.

2) Intersecções parciais de sentido (com variadas amplitudes). No par mismo - "mesmo", uma intersecção semântica se dá numa porção muito pequena das possibilidades de uso de "mesmo" no PB. Os adjetivos mismo - "mesmo" indicam ambos identidade (escuchamos la misma canción varias veces "ouvimos a mesma música várias vezes"). Vários outros valores de "mesmo" no português não são expressos por mismo no espanhol. ${ }^{5}$ Intersecções parciais de sentido entre cognatos podem envolver partes mais amplas ou menos amplas do espectro semântico global das palavras assemelhadas. Cabe perguntar se poderíamos incluir casos como o de mismo"mesmo" numa contagem de cognatos homossemânticos entre o português e o espanhol ou se essa seria uma simplificação distorcedora da questão dos cognatos e falsos cognatos entre essas duas línguas e do jogo complexo de transparências e opacidades que as palavras assemelhadas têm o potencial de gerar para a compreensão dos falantes de uma pelos falantes de outra.

3) Diferentes conotações. Considerando o par "empregado" empleado, no PB a palavra "empregado" ganhou conotações de desprestígio social (Celada: 1999). Em PB, fala-se dos

5 Para exemplos num estudo mais detalhado, ver Jacobi (2002). 
"funcionários" de uma empresa / instituição para referir-se a tarefas administrativas ou técnicas que requerem mais escolarização, e não se costuma usar a palavra "empregados" nesses casos. No PB, a palavra "empregado" se aplica ao campo das profissões que costumam ser associadas a pouca escolaridade, menor qualificação técnica, menor remuneração e menor prestígio social. Em espanhol, fala-se sem problemas de empleados de empresas no caso de profissões que, por exigirem tradicionalmente uma formação mais especializada, gozam de maior prestígio social.

4) Circunscrição a diferentes dominios discursivos. A questão da distribuição das formas de tratamento nos diferentes domínios discursivos do português e do espanhol é complexa em si mesma e em suas relações de equivalência, entre outros motivos, por envolver variação de dialeto e de registro. ${ }^{6}$ Seria possivel contabilizar, entre as palavras semelhantes do português e do espanhol, o par tú - "tu", num estudo estatístico como o de Richman, sendo que as distribuições no uso dessas palavras gráfica e acusticamente assemelhadas diferem de maneira complexa entre os dois idiomas?

A partir desses poucos exemplos de diferentes complexidades envolvidas no exame dos cognatos léxicos entre o português e o espanhol, parece ser possível concluir que um estudo como o de Richman interessaria como indicador quantitativo porque traça uma perspectiva geral da proximidade gráfica (e em menor medida acústica) do acervo lexical entre o par português-espanhol, ou seja, indica em que medida podemos reconhecer entre essas duas línguas uma origem etimológica comum. Contudo, os números que apresenta deveriam ser interpretados com cuidado dentro do panorama que tentamos esboçar acima. As distâncias e proximidades entre o léxico dos dois idiomas envolvem sutilezas e complexidades impossiveis de mensurar dentro da dicotomia falsos $v$ s verdadeiros cognatos. Isso colocaria ressalvas a estudos quantificadores calcados nessa dicotomia e feitos no nível do sistema da língua (e não do uso). Para levar

6 Para exame de aspectos desta questão, ver Cintrão (2004).

TradTerm, 12, 2006, p. 69-104 
em consideração questões como as esboçadas acima, uma quantificação da proximidade lexical envolveria um trabalho prévio mais minucioso de classificação de tipos de cognatos na qual basear os cálculos estatísticos. A indicação de que no estudo mencionado trabalhou-se dicotomicamente (cognato vs não cognato) com a aproximação semântica entre os cognatos que quantifica parece indício suficiente de uma simplificação que não permitiria considerar tal estudo como um indicador válido de uma dimensão geral do grau de proximidade entre o português e o espanhol no nível lexical. Contudo, ele parece dar uma boa idéia da medida de uma "proximidade percebida" superficialmente por falantes de uma lingua com parco domínio da outra.

\subsection{Palavras gramaticais e sintaxe}

Ao considerar os cognatos diferenciando entre palavras lexicais e palavras gramaticais, cabe destacar que o espanhol e o português têm, entre seus cognatos, uma grande quantidade de palavras gramaticais, como por exemplo preposições.

Por outro lado, as diferenças entre as possibilidades de combinação (incluindo regimes preposicionais de verbos e substantivos) que palavras assemelhadas têm em cada um dos idiomas parece uma questão importante, ao se analisarem potenciais fatores de facilitação ou interferência na compreensão interlingüística, na aprendizagem de uma língua por falantes da outra, e na tradução entre essas linguas. Como discutiremos mais adiante, temos indícios de que a probabilidade de interferência na tradução entre o português e o espanhol é maior entre palavras gramaticais e estruturas sintáticas.

Cabem ainda alguns exemplos relativos às regências preposicionais e às combinações possiveis (collocations). Em espanhol, fala-se em formar parte de algo enquanto que em PB se diria "fazer parte de" algo. Em espanhol, a articulação entre um verbo de movimento e o meio de transporte com que se realiza o movimento se faz com a preposição en (viajar en tren), enquanto que em PB se faz com a preposição "de" (viajar de trem). Numa 
perífrase com o verbo ir ou venir e um infinitivo, o espanhol interpõe necessariamente a preposição a (fuimos $\underline{a}$ bailar, vine $\underline{a}$ verte), diferentemente do $\mathrm{PB}$ ("fomos dançar", "vim ver você"). Há uma série de usos assimétricos de preposições assemelhadas no plano do significante. Essa diferença pode ser mais bem compreendida se nos lembrarmos de que as preposições são, no português e no espanhol, uma categoria com elevado número de elementos (ou usos) praticamente vazios de sentido lexical.

O complemento direto preposicionado do espanhol é uma dessas assimetrias nos usos preposicionais. Constitui uma notável dificuldade de aprendizagem do espanhol por brasileiros no que se refere à produção na L $2,{ }^{7}$ mas em certas estruturas pareceria não colocar dificuldades para a compreensão auditiva ou leitora. No entanto, em combinação com outras diferenças sintáticas entre os dois idiomas, pode provocar importantes distorções de interpretação de um enunciado.

Como se sabe, a principal função do complemento direto preposicionado no espanhol é desambiguadora: a preposição $a$ marca o sintagma nominal (SN) que funciona como objeto direto (OD), em oposição ao SN que funciona como sujeito do verbo. Só tem relevância e vigência quando, semanticamente, o SN em função de OD apresenta um ser animado e individualizado que poderia ser o sujeito (agente) do verbo. Essa necessidade de desambiguação não pode ser dissociada da maior flexibilidade do espanhol na estrutura canônica da oração (SVO), quando comparado ao PB. A maior freqüência com que o sujeito pode aparecer posposto ao verbo, no espanhol, tem o potencial de gerar problemas de compreensão para os falantes do PB. O seguinte exemplo foi observado em aula de L2:

\section{(1) ¿Ha llamado Ana?}

O enunciado (1) costuma gerar dificuldades de identificação do sujeito para estudantes brasileiros de E/LE, com conseqüentes equívocos de interpretação. Há uma forte tendência a que os estudantes interpretem que uma pessoa não menciona-

7 Para um estudo desta questão, ver Yokota (2001). 
da (categoria vazia) funciona como sujeito de ha llamado, ou mesmo a interpretar que esse sujeito não explicitado seria o interlocutor, e tende-se a interpretar que Ana (o sujeito) é objeto de ha llamado. Um falante do espanhol perceberia intuitivamente que, se Ana fosse OD, a preposição $a$ apareceria necessariamente antes desse SN ( $\underline{a} A n a)$. Um dos motivos desse equívoco de atribuição de papéis sintáticos parece ser a baixa probabilidade de que um falante do PB colocasse o sujeito de "telefonar" depois do verbo, numa pergunta desse tipo. Em vez disso, tenderia a construir uma frase como: “(A) Ana ligou / telefonou?” Como em PB se usaria uma preposição entre "telefonar" e seu objeto ("Ligou para (a) Ana?"), no caso de "Ana" ser o objeto, llamar acaba sendo entendido como sua palavra assemelhada no português "chamar", e não como "ligar / telefonar", e se interpreta: "E Chamou (a) Ana?" Em outras palavras, em contextos sintáticos nos quais o português resolve uma possivel ambigüidade dos papéis de sujeito e OD valendo-se da ordem dos elementos na oração, o espanhol resolve a ambigüidade potencial com o mecanismo de introduzir o OD animado e individualizado com a preposição $a$, em contraste com a ausência da preposição no caso de um SN do mesmo tipo ser o sujeito. Isso tem reflexos na compreensão oral ou leitora de um falante do PB ao ponto de derivar numa interpretação equivocada do sentido do verbo llamar no enunciado (1).

Isso posto, em que critérios poderiamos nos basear para decidir se a preposição $a$ do espanhol e a preposição "a" do português são cognatos homossemânticos? Deveríamos criar também as categorias de cognatos "homossintáticos" e "heterossintáticos", para aplicar a palavras gramaticais que não têm valor propriamente "semântico" ou lexical, mas sim relacional? Podese dizer que a predominância da ordem oracional SVO se dá de modo similar entre o português e o espanhol, após examinar o equívoco de interpretação de (1)?

A análise do léxico em cruzamento com a sintaxe e com usos possiveis corrobora que esmiuçar as assimetrias entre os supostos cognatos do português e do espanhol nos leva bastante além de associar palavras graficamente assemelhadas a um dos pólos da dicotomia verdadeiros $v$ s falsos cognatos. Além dis- 
so, a questão da proximidade transcende as considerações de semelhanças gráficas em relação com semelhanças no sentido referencial entre palavras isoladas, e entra no plano das relações do léxico com a sintaxe. ${ }^{8}$

Importa deixar esboçada a complexidade das similitudes entre esse par de línguas, sem deixar de assumir que há de fato uma importante semelhança de bases lexicais (pelo menos etimológica) entre o português e o espanhol, realmente facilitadora da compreensão para os falantes de uma que desconhecem por completo a outra.

\subsection{Uma proposta empirica de mensuração de distâncias no plano do uso}

Eres Fernández (1995) procura uma expressão estatística do grau de compreensão espontânea que um brasileiro pode chegar a ter do espanhol graças à proximidade entre as duas línguas, mas procura fazê-lo junto a usuários em vez de fazê-lo no plano do sistema lingüístico lexical. Ao considerar de forma mais holística a língua (em vez de classificar palavras de acordo com a dicotomia cognatos $v$ s falsos cognatos), seu estudo chega a números diferentes dos de Richman, e seus resultados parecem mais ajustados ao panorama de similitudes e diferenças que procuramos esboçar acima observando alguns exemplos: "lusofalantes que nunca estudaram sistematicamente o espanhol entendem aproximadamente $46 \%$ do idioma falado e $58 \%$ do idioma escrito". ${ }^{9}$

Esse índice de compreensão espontânea é sem dúvida elevado, mas sugere uma aproximação média, corroborando a percepção de González \& Kulikowski (1999: 16) de que o português e o espanhol podem ser consideradas línguas "moderadamente próximas".

8 Para observações contrastivas também no nível discursivo, ver González \& Kulikowski (1999).

9 Citamos a partir de Durão (2002: 16). 


\subsection{Distância real e distância percebida}

As duas últimas autoras, preocupadas em responder à pergunta de "como determinar a justa medida de uma proximidade" entre o português e o espanhol, no cenário da aprendizagem de E/LE por brasileiros, apontam para um outro fator além de uma determinação objetiva da medida desse distanciamento. Além da "distância real", tem efeitos importantes a "distância percebida" entre as línguas pelo aprendiz.

Nesse sentido, a história de como os falantes de português e espanhol têm encarado as relações entre seus idiomas e culturas parece ter sido, via de regra, a de uma acentuada superficialidade calcada no pressuposto igualmente superficial de uma "quase-igualdade" entre as duas linguas, que outorgaria uma competência automática dos falantes de uma na outra e que dispensaria qualquer estudo ou aprendizagem aprofundados ou prolongados, mesmo no caso do trabalho profissional com esse par de línguas, como no caso da tradução.

A medida da proximidade-distância na compreensão espontânea entre o português e o espanhol parece combinar, assim, dois aspectos.

1) Distância real. Entendemos que deveria ser quantificada a partir de parâmetros objetivos e procedimentos empíricos no plano do uso, como no caso do estudo de Eres Fernández et alii ([s/d]). Para a habilidade de compreensão, consideraremos a distância de acordo com a proposta de Eres Fernández (1995), de 46\% do idioma falado e 58\% do idioma escrito. Esses números apontam para uma proximidade pouco maior que média, para a compreensão leitora.

2) Distância percebida. Numa aproximação inicial dos falantes de uma pelos falantes de outra, a distância percebida tende a basear-se em grande medida em similitudes apenas superficiais das bases lexicais, posto que a superficie lexical é a parte mais imediatamente perceptivel de uma lingua. Deste último ponto de vista, supomos que o estudo de Richman possa nos dar um parâmetro de medida: aproximadamente $90 \%$ de proximidade percebida. Isso parece ser válido especialmente no caso da língua escrita culta, registro em que os dois idiomas parecem chegar à sua maior aproximação. 


\subsection{Cálculo de distância e proximidade tradutórias: uma medida sintática?}

Uma perspectiva diferente e complementar é sugerida por outro estudo empírico no qual também se procurou uma forma de captar estatisticamente a distância entre o português e o espanhol (neste caso, uma chamada "distância tradutória"), comparando-a com a de outro par de línguas: português e inglês.

Partindo dos procedimentos técnicos da tradução de Vinay \& Dalbernet (1958), Aubert (1998) elaborou uma classificação de treze modalidades de tradução para aplicar à análise quantitativa de corpora de tradução. O método tem sido aplicado a esse tipo de corpora também para fins de lingüística comparada, no cálculo do distanciamento-proximidade tradutório entre pares lingüísticos (Corrêa: 2000).

Silva (1992) aplicou o método das modalidades à tradução de um conto em PB para o inglês e para o espanhol. Sua hipótese inicial era a de que a tradução para o castelhano mostraria maior incidência das modalidades da tradução literal e da transposição ${ }^{10}$ do que a tradução para o inglês, e interessava-lhe determinar valores para essas diferenças de proximidades-distâncias (Aubert, 1998: 114). A conclusão não corroborou totalmente a hipótese. Sobre os resultados estatísticos do estudo, Aubert (1998: 115) considera:

[...] a despeito da proximidade tipológica evidentemente maior entre português e castelhano do que entre português e inglês, em termos quantitativos tal diferença, embora estatisticamente significativa, não parece ser tão elevada assim. [...] se compararmos os valores para tradução

\footnotetext{
10 Tradução literal. Observa-se: (i) o mesmo número de palavras, (ii) na mesma ordem sintática, (iii) empregando-se as 'mesmas' categorias gramaticais e (iv) contendo as opções lexicais que, no contexto específico, podem ser tidas por sinônimos interlingüísticos. Transposição. Um dos três primeiros critérios definidores da tradução literal deixa de ser satisfeito (por mais 'literais' que os respectivos significados se apresentem, não serão considerados na modalidade "tradução literal"). Modulação. Na tradução de um segmento textual os significados são parcial ou totalmente distintos, mas mantém-se, em termos genéricos, o mesmo sentido. Para definições e exemplificações detalhadas das treze modalidades, ver Aubert (1998).
}

TradTerm, 12, 2006, p. 69-104 
literal em ambas as versões, a diferença é muito marcante. Mas, se a esses forem somados os valores correspondentes à transposição (os quais [...] representam, em conjunto, tudo aquilo que comumente é concebido como literalidade em tradução), atingem-se valores próximos a um equilibrio $(78,3 \%$ para o castelhano contra $74,1 \%$ para o inglês).

Esse resultado parece indicar algum grau de "distorção" provocada por características do método. A partir mesmo do senso comum, não é difícil argumentar no sentido de que o distanciamento do par português-inglês é acentuadamente maior do que o do par português-espanhol. Um falante do português sem nenhum contato com o inglês entenderá muito pouco ou praticamente nada quando exposto pela primeira vez a uma produção naquele idioma, especialmente se essa produção for oral, e não escrita. Um falante do português que nunca tenha tido contato com o espanhol entenderá muito mais ao ser exposto pela primeira vez a um texto em espanhol, embora essa compreensão certamente provavelmente diminuísse para a produção oral, e embora já se tenha notado (Bruno: 2001) que muitas vezes acredita-se estar entendendo quando na realidade não se está. Para um texto escrito, é ainda maior a possibilidade de que um falante do português entenda realmente muito.

A que se deveria a "distorção" que o método das modalidades estaria gerando nessa medida de distanciamento? Entendemos que se deva à falta de um dispositivo para quantificar também a semelhança lexical, as etimologias comuns a que nos referiamos anteriormente. Sem esquecer as ressalvas feitas sobre a compreensão aparentemente fácil de grande número de palavras entre o português e o espanhol, é preciso considerar que os falantes realmente identificarão, num primeiro contato, um elevado número de palavras, inclusive palavras relacionais (gramaticais) e morfemas, no caso de linguas tipologicamente mais próximas. Justamente essa proximidade de bases lexicais confere ao par português-espanhol uma característica de elevado grau de transparência inicial, especialmente na modalidade escrita, e especialmente no que chamávamos de "distância percebida". 
O estudo de Richman parecia pecar por um isolamento redutor de semelhanças gráfico-acústicas de bases lexicais. O método das modalidades talvez se mostre extremado no sentido oposto, ao não ter entre suas categorias de análise um dispositivo que permita considerar, na quantificação, a semelhança de bases lexicais. Esta semelhança parece dificultar a percepção de diferenças importantes que há entre o português e o espanhol em outros estratos lingüísticos e gerar um descompasso entre proximidade real e proximidade percebida. A semelhança de bases lexicais precisaria ser computada, se quiséssemos medir não apenas a proximidade-distância em termos de modalidades mais ou menos distantes do "grau zero" da tradução, ou medir a distância tradutória em termos de menor ou maior linearidade na transposição das palavras, mas também quanto ao grau de transparência imediata que os falantes de uma língua percebem na outra.

Por outro lado, a ausência de dispositivos que meçam esse aspecto lexical da distância-proximidade torna o método das modalidades bastante interessante para observar o português e o espanhol em suas relações contrastivas, porque o que ele parece medir são, sobretudo, as distâncias sintático-estruturais e expressivas entre os pares em textos escritos. É como se nos permitisse realizar medições excluindo aspectos fonéticos e semelhanças de significantes no léxico, selecionando apenas os aspectos relativos predominantemente aos fatores estruturais (especialmente os sintáticos).

As modalidades de transposição e modulação, especialmente, são dispositivos do método que permitem registrar quantitativamente se a ordem das palavras na frase é diferente ( $¿ H a$ llamado Ana? - "A Ana ligou?"); se para uma palavra de uma língua há duas na outra (ha llegado - "chegou"; de la - "da"). Permitem medir se são usadas diferentes estruturas sintáticas para expressar as "mesmas coisas", se um sujeito em uma construção do português passa a OI numa do espanhol e vice-versa, ou seja, se as linguas trabalham com diferentes papéis sintáticos para os mesmos papéis temáticos ("Eu gosto de chocolate"Me gustan los chocolates / Me gusta el chocolate); se uma formulação no plural passa ao singular de uma língua a outra (Los 
argentinos somos asi - "Brasileiro é assim mesmo"); se uma língua usa artigo onde outra não usa ("E o Carlos?" - ¿Y Carlos?; "Eu sou da América" - Soy de América); se há mudança de categoria de palavras para expressar a "mesma coisa" (“-Você quer? / / -Quero" [resposta com verbo] vs-¿Quieres? / ¿Querés? / / $\underline{\text { Sí }}$ [resposta com advérbio]); se o que se omite em uma língua se expressa na outra ("Eu não sabia" - No lo sabia), ou seja, se há elementos expressos em uma língua onde em outra não há,

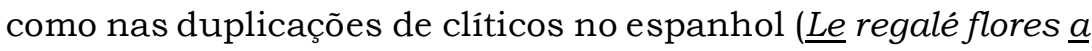
Marta - "Eu dei flores para a Marta") ou na presença obrigatória de clíticos como elementos de coesão, frente à categoria vazia para o sujeito nessa função coesiva, no espanhol (Te $\underline{\text { lo }}$ traigo mañana - "Eu trago amanhã"); ou ainda as diferentes colocações pronominais nos dois idiomas ( Ya se habia acostado - "Já tinha se deitado"); a variação entre o uso de pronomes tônicos e átonos entre ambos ("A mãe dele disse..." - $\underline{\text { Su }}$ madre dijo; "Então eu disse pra ele que...." - Entonces le dije que..."); as diferentes distribuições de freqüência de uso de passivas sintéticas e analíticas nos dois idiomas (La producción de un texto se puede describir como un proceso... - "A produção de um texto pode ser descrita como um processo..."; diferentes formas de enunciar eventos ("O vaso caiu (da minha mão) e quebrou / Eu deixei cair o vaso e ele quebrou" - Se me cayó el florero y se rompió) ${ }^{11}$ etc.

É nesses aspectos que a distância entre o português e o espanhol se assemelha mais àquela entre o português e o inglês.

Isso permitiria formular a relação entre o par espanholportuguês como a de uma grande proximidade de raízes etimológicas/bases lexicais, no léxico e na morfologia, combinada com uma importante distância sintática em lugares pontuais, mas cruciais (para a aquisição, por exemplo), como o uso de pronomes-sujeito e dos clíticos, as diferentes disposições das palavras nas frases, as diferentes formas de enunciar.

\footnotetext{
11 Alguns exemplos foram extraídos de trabalhos referidos na bibliografia final.
} 


\subsection{Especificidades do par e primeiras conclusões para a tradução}

Por um lado, o exposto até aqui parece permitir considerar que, de fato, não se pode falar de iniciantes na aprendizagem de lingua estrangeira entre o par português-espanhol como se fala de iniciantes em pares tipologicamente mais distantes, como por exemplo, português-alemão, espanhol-inglês, especialmente no que diz respeito às habilidades de recepção, e muito especialmente no que se refere à compreensão escrita.

Por outro lado, o resultado do estudo de aplicação do método de modalidades nos dá um suporte empírico-quantitativo para aquilo que se percebe em observações da prática profissional ao trabalhar com o par português-espanhol: o par apresenta zonas de importantes distâncias sintáticas e discursivas. Também é importante ressaltar que há graus diferenciados de dificuldade de aquisição entre as habilidades de produção e de recepção.

Na tradução direta escrita, a destreza requerida na L2 é a compreensão leitora. Poderíamos nos perguntar se a competência tradutória (CT) para a tradução direta no par português-espanhol ficaria mais especialmente focada na habilidade do tradutor para o uso de estratégias mais refinadas de interpretação da macroestrutura textual, de habilidades de interpretação em níveis mais complexos da tessitura e do discurso, como coesão e coerência, e na competência de escrita na LM (e sabemos bem o quanto essa habilidade pode ser exígua entre nativos de uma lingua).

Outra possivel implicação para a didática de tradução é que pode ser especialmente necessário "colocar uma lupa" ${ }^{12}$ no espanhol para os estudantes brasileiros em certas regiões estruturais e discursivas nas quais diferenças significativas parecem ficar "invisiveis" para quem tem o PB como LM, como efeito de um tipo de ofuscamento pelas semelhanças na superficie das bases lexicais.

12 Tomo emprestada a imagem escutada da Profa. Dra. María Teresa Celada (Universidade de São Paulo). 
Além de precisar levar em conta uma série de pontos contrastivos que têm sido estudados especialmente por serem regiões de dificuldades da perspectiva da aquisição de espanhol como L2 por falantes do português, ${ }^{13}$ os tradutores se defrontam a cada momento com questões culturais e com a heterogeneidade interna de ambas as línguas. As distâncias estruturais e discursivas dificilmente poderão ser resolvidas pelo tradutor com o uso de dicionário ou outros materiais de consulta (como poderiam ser resolvidos problemas com os falsos cognatos), mas apenas com um bom tempo de contato atento com ambas as línguas. No entanto, a sensação de compreensão automática gerada especialmente pela semelhança de bases lexicais faz com que bilíngües de outros pares lingüísticos se aventurem sem preparo suficiente (por vezes, sem preparação mínima) na tradução desse par, o que gera traduções que só demonstram, nas palavras de García-Medall (2000: 23):

(a) un alto grado de intrusismo profesional, por parte de aficionados;

(b) un escaso conocimiento gramatical del portugués y del español;

(c) una escasa o nula competencia traductora, como resultado inevitable de (a) y de (b).

Por fim, vale lembrar que a tradução envolve questões que extrapolam as diferenças estritamente contrastivas termo a ter-

\footnotetext{
13 Exemplos importantes são os seguintes: morfologia e usos verbais; o verbo gustar e o campo da expressão da afetividade, opiniões e sensações (repleto das chamadas "construções oblíquas", no espanhol); formas de tratamento (em suas interfaces com coesão, variação e cultura); estruturas em que o português utiliza o futuro de subjuntivo ou o infinitivo flexionado; subordinadas em que as distribuições de uso de indicativo-subjuntivo / infinitivo-subjuntivo divergem entre as duas linguas; diferentes distribuições de uso de passivas sintéticas (com se) e analíticas (com ser) nos dois idiomas; diferentes usos de gerúndios, de determinantes, de pronomes em geral, especialmente dos clíticos no espanhol, mas também os diferentes valores semânticos da explicitação do pronome-sujeito, diferentes freqüências de uso de possessivos átonos e tônicos; diferentes possibilidades e freqüências da ordem dos elementos na oração, diferentes usos preposicionais.
} 
mo ou de estruturas sintáticas entre um par de idiomas específico, questões que se referem ao ato tradutório e pedem algum conhecimento sobre tradução, como o peso das tipologias textuais e dos objetivos para considerar a "fidelidade" na tradução; como as especificidades da linguagem de acordo com dominios discursivos determinados, as quase sempre dificeis decisões referentes a variações dialetais etc.

\section{Aspectos da interferência em tradução}

Ao explicar a transferência a partir do empréstimo, Corder parecia considerar especialmente as habilidades de produção na L2, mas sua explanação esclarecia também a interferência na compreensão leitora: a maior incidência de semelhanças lexicais e estruturais entre um par lingüístico pode levar o leitor não proficiente na L2 a aplicar, com maior desenvoltura e autoconfiança, seu conhecimento da LM para interpretar textos na L2 (por vezes, inclusive, acreditando estar entendendo o que, de fato, não está). Assim, a hipótese de Corder para a transferência em aquisição pode explicar a interferência em tradução, no caso de uma proficiência lingüística incipiente na L2. No entanto, no caso da tradução direta por um bilíngüe proficiente, a aparente interferência da L2 sobre a LM deve ser ativada por um fenômeno de outra natureza, e não pelo mecanismo do empréstimo.

Modelos propostos pela Psicolingüística, pela Semântica Cognitiva e pela Teoria da Relevância postulam mais de uma fase no processamento dos sentidos lingüísticos, assim como diferentes localizações cerebrais para cada uma dessas fases.

Alguns desses modelos concebem que a organização conceitual da memória de longo prazo tem considerável autonomia da linguagem verbal. Isso permite construir hipóteses explicativas mais verossímeis que a do empréstimo para interferência em tradução, no caso de bilíngües proficientes. Elementos desses modelos serão esboçados nos próximos subitens, com vistas a considerar seu potencial explicativo para a interferência em tradução. 


\subsection{Tipos Cognitivos (TC): independência entre conceito e linguagem verbal}

Construtos teóricos formulados com os nomes de "tipo cognitivo" (TC), por um lado, e de "quadros" ou "cenas" mentais, por diferentes teóricos, parecem poder se complementar como explicações do processamento dos sentidos. Neste subitem trataremos do primeiro.

O TC seria uma entidade mental complexa, assim explicada por Eco (1997): ${ }^{14}$ “[...] em nossa mente deve existir um código interno ou subverbal que catalogue as percepções (inclusive das palavras) e as subdivida em tipos cognitivos (TC), que não são palavras, mas entidades mentais não definidas totalmente" (destaque do autor).

Segundo essa hipótese, o TC pode preceder a (e prescindir da) linguagem verbal. Eco considera o exemplo da inserção do cavalo na sociedade dos astecas pelos espanhóis:

[...] depois de ver alguns cavalos, eles [astecas] devem ter criado um padrão morfológico, não muito diferente de um modelo 3D, e é a partir dessa base que devemos inferir a consistência de seus atos perceptivos. Não obstante, ao falar de TC não me refiro somente a uma espécie de imagem, nem a um conjunto de elementos morfológicos ou de características motrizes [...] No final das contas, podemos afirmar que o TC do cavalo possuía desde o princípio um caráter multimídia (Eco, 1997: 109).

Se for assim, o que individualmente precisamos para estruturar cognitivamente a percepção do mundo externo não passa necessariamente por nominar os objetos, mas precisariamos do TC, que nos permitiria "identificar uma sensação ou um objeto e classificá-lo mentalmente, de modo a tornar a estrutura de nosso aparelho perceptivo-cognitivo cada vez mais complexa e diferenciada". Certamente a palavra auxilia e refina esse processamento da experiência, mas não seria condição indispensável para ele: "não era necessário nominar o objeto-cavalo para reconhe-

\footnotetext{
14 Todas as citações de Eco a partir de Osimo (2001), "A leitura. Segunda Parte, 7".
} 
cê-lo, da mesma maneira que posso notar uma sensação interna desagradável embora indefinivel e reconhecer que é a mesma que havia sentido no dia anterior" (Eco, 1997: 111).

Explicando o processamento dos sentidos com base nesse modelo, Osimo considera que, ao interpretar, "comparamos os acontecimentos com um tipo determinado". No caso da linguagem verbal, ao decodificar um enunciado no processo de leitura, depois de correlacionar evento gráfico com tipo gráfico (reconhecer a palavra), executamos uma segunda comparação entre tipo gráfico e tipo conceitual, para identificar o significado de uma palavra baseando-nos no TC que aquela palavra ou padrão gráfico ou sonoro evoca.

Assim, os TCs seriam o núcleo da associação entre vários elementos, um ponto de confluência numa rede de associações que pode reunir diferentes tipos de percepção sensorial (elementos visuais, olfativos, táteis,...), diferentes conteúdos valorativos (eufóricos ou disfóricos), conexão com conjuntos de outros tipos cognitivos (campos semânticos), possibilidades combinatórias dentro de frases, quando estão manifestos em palavras (lugares e padrões sintáticos nos quais podem/devem aparecer).

Entre os componentes que contribuem para configurar o TC pareceriam estar os elementos potencialmente contíguos, os que a experiência de mundo aponta que mais provavelmente podem ocorrer associados àquele TC em questão.

\subsection{Redes conceituais e competência em tradução}

Ao falar da Semântica Cognitiva, González Nieto (2001: 128) diz que "qualquer teoria do significado léxico deve partir de sua organização em redes, quer se trate de redes de conceitos, como em Psicologia, ou de redes de palavras ou de significados, como em Lingüística". Ao descrever a estrutura dessas redes, a perspectiva cognitiva também sugere que, no processamento dos sentidos, desempenham um importante papel os protótipos e os estereótipos das entidades e fenômenos.

A hipótese de Minsky (1975) sobre a organização cognitiva da experiência propõe um saber organizado em quadros cogniti- 
vos ou sociocognitivos, à maneira de situações estereotipadas. Quando alguém se depara com uma situação nova (ou efetua uma modificação no seu conhecimento prévio), seleciona uma estrutura complexa conservada na memória ("quadro"), capaz de se encaixar na realidade com a alteração de alguns detalhes, se for preciso. O "quadro" (frame) de uma casa típica terá lugares reservados para a cozinha, o teto e outros elementos obrigatórios, e lugares para elementos opcionais, como a piscina. Cada um desses lugares pode constituir um novo quadro. Uma casa existente no mundo será representada cognitivamente preenchendo os lugares do quadro com "saturadores" particulares dessa casa. Esse modelo permitiria explicar processos inferenciais: ativado o quadro de uma ida a um restaurante, dá-se por sabido que deve ter componentes como sentar-se à mesa, pagar a conta, etc. Tal proposta teórica também oferece um ponto de vista interessante para entender a compreensão do discurso verbal como "processo que consiste em adaptar o que nos é dito ao modelo estrutural estabelecido pelo que já sabemos" (Charniak, 1979, apud Brown \& Yule, 1983 [1993]: 294).

Sendo assim, teríamos representações organizadas como unidades complexas de conhecimento estereotipado, armazenadas na memória como um conjunto de fácil acesso e que poderia ser ativado na totalidade ao se ativar um de seus componentes representativos.

Mas, por algum motivo, pode acontecer que, ao traduzir, um bilingüe efetue uma passagem direta de estruturas lingüísticas da L2 a estruturas lingüísticas da LM, sem passagem intermediária pelo nível dos processamentos cognitivo-pragmáticos, mesmo sendo bastante proficiente na L2 e tendo recursos para entender bem o que se expressa nela. Presas se refere a esse fenômeno como "o poder hipnótico" do texto de partida:

[...] ao passo que a interferência tem sido freqüentemente descrita e classificada do ponto de vista lingüistico, ainda não há hipóteses convincentes, do ponto de vista psicolingüistico, para explicar o poder hipnótico que o texto-fonte exerce sobre o tradutor, mesmo quando ele ou ela é altamente proficiente na lingua estrangeira e está traduzindo da L2 para a L1. (Presas, 2000: 26) 
Tanto Presas (2000) quanto Snell-Hornby (1988) consideram que o processamento bilíngüe que vincula diretamente elemento lingüístico a elemento lingüístico é em princípio inadequado em tradução. Kussmaul (2004) aponta que funcionaria naqueles lugares em que a tradução poderia ser realizada mecanicamente, por tradutores automáticos ou memórias de tradução, mas que, no caso dos problemas de tradução que pedem retextualizações e soluções criativas, o tradutor teria que mobilizar as estruturas mentais de representação, especialmente a visualização. Há um grande consenso em torno da desmobilização de automatismos descontextualizados em tradução (no nível da superficie das microunidades das formas lingüísticas), em favor de um processamento mais alerta e complexo dos sentidos e funções, como fator essencial para o desenvolvimento da competência tradutória.

O processamento lingüistico que levaria a melhores resultados no produto seria o que conduzisse à reformulação de uma estrutura lingüística na L2 em outra na LM mediada pela contextualização, pela visualização local (palavra) e global (função da palavra na "cena" geral do texto), pela compreensão ampliada das questões lingüísticas como envolvendo dois sistemas culturais distintos, por fatores pragmáticos e discursivos.

\subsection{Automatismos de decodificação e o "poder hipnótico" do texto de partida}

Durão indicava que a Psicolingüística fala de uma capacidade inata para detectar padrões invariantes em situações novas de aprendizagem, com o fim de reduzir a quantidade de informação armazenada e processada. Haveria uma tendência a anular diferenças e identificar o elemento novo com uma categoria já conhecida. Mesmo fora de situações de aprendizagem e aquisição de novos conhecimentos, essa tendência parece operar, podendo explicar nossa capacidade de decodificar textos como o da seguinte mensagem que circula na Internet em vários idiomas:

De aorcdo com uma pqsieusa, não ipomtra em qaul odrem as lrteas de uma plravaa etãso, a úncia csioa iprotmatne é 
que a piremria e útmlia lrteas etejasm no lgaur crteo. $\mathrm{O}$ rseto pdoe ser uma ttaol bçguana que vcoê pdoe anida ler sem pobrlmea. Itso é poqrue nós não lmeos cdaa lrtea isladoa, mas a plravaa cmoo um tdoo.

O cérebro ajusta rapidamente cada unidade desse texto a uma palavra da LM reconhecivel, por haver um determinado contexto mínimo como ponto de apoio cognitivo.

Sperber \& Wilson (1986 [1994]: 221) notam que o contato com um enunciado na LM é um estímulo impossivel de ignorar cognitivamente. Mesmo quando não dirigido àquele ouvinte, é impossivel que um enunciado em LM que chegue aos seus ouvidos não seja imediatamente segmentado e interpretado como estrutura proposicional. Segundo esses autores, tal fenômeno indica que o sistema decodificador de enunciados lingüísticos na LM tem as mesmas características que a de outros sistemas perceptivos de caráter automático, como a visão. "Não podemos escolher ver as coisas em preto-e-branco em vez de vê-las coloridas". Também não podemos escolher não decodificar enunciados na LM.

Assim, segundo a diferenciação dos módulos mentais de Fodor (1986), o sistema de decodificação lingüística, nos níveis iniciais de segmentação do continuum sonoro e de atribuição de uma forma proposicional, seria um sistema de entrada e não faria parte do sistema de processamento central, nas estruturas de memória conceituais.

Esto sugiere, a su vez, que si la comprensión se define como un proceso de indentificación de la intención informativa del hablante, la descodificación lingüistica no será tanto parte del proceso de comprensión como algo que precede al verdadero trabajo de comprender, algo que simplemente proporciona un aducto para la parte principal del proceso de comprensión. (Sperber \& Wilson, 1986 [1994]: 221)

Tendências cognitivas a automatismos de decodificação como as indicadas acima podem ser capazes de explicar por que, na tradução, acontecem decalques inusitados da L2 na LM também no caso de bilíngües proficientes. Se a interferência visivel no produto de uma tradução pode se dever também a um auto- 
matismo de processamento, ${ }^{15}$ é verossímil supor que um elevado número de palavras de bases lexicais semelhantes às da LM (línguas próximas) possa disparar e/ou incrementar a tendência à atribuição automática de uma estrutura proposicional a um enunciado da L2 como se ele fosse originalmente um enunciado pertencente à LM, também no caso de um bilíngüe proficiente em estado mental de desatenção por sobrecarga cognitiva, sobrecarga essa atribuivel aos limites de capacidade da memória de trabalho. Essa tendência ao automatismo poderia, então, explicar o dito "poder hipnótico" do texto de partida, no caso de bilingües proficientes.

Séguinot (1990) observou que tradutores experientes "erram" mais no final das frases do que no início delas. Os exemplos de erros que apresenta têm as características de uma interferência da L2 sobre a LM (decalques da L2, freqüentemente estruturais). Isso se explica porque, no final das frases, a memória de trabalho está mais sobrecarregada. Nas revisões, os tradutores experientes costumam corrigir esses erros. ${ }^{16}$

Séguinot ainda observa que bons estudantes de tradução, quando chegam aos últimos anos da faculdade, mostram textos mais bem elaborados em estratos lingüísticos mais complexos (sintáticos, por exemplo), ao mesmo tempo em que começam a cometer, em estratos menos complexos (niveis lexicais), erros que não cometiam nos primeiros anos (muitas vezes na forma de decalques de falsos cognatos). Ao que parece, o foco na reformulação sintática, estilística e/ou pragmática ocupa sua memória de trabalho de modo a não restar nela capacidade para a atender aos falsos cognatos no nível lexical. A capacidade da memória para processar vários níveis lingüísticos simultaneamente se mostra mais desenvolvida em tradutores experientes. Séguinot supõe que esse incremento de capacidade de processamento venha apenas com o tempo, como conseqüência do rit-

15 E não apenas a um reflexo, na produção, da interferência devida ao empréstimo como mecanismo facilitador da compreensão para sujeitos não proficientes na L2.

16 O que reforça a importância de revisões cuidadosas das traduções, assim como de uma revisão final feita (ou algumas revisões finais feitas) sem o texto original (ativador de interferências) em vista. 
mo mais acelerado que o grande volume de trabalho impõe aos tradutores no exercício real da profissão.

Especialmente naqueles lugares onde palavras e estruturas entre um par lingüístico podem guardar uma semelhança que é puramente superficial (forma e ordem das letras na palavra ou ordem das palavras na oração), o automatismo da fase inicial do processamento lingüístico no módulo decodificador (em conjunto com limitações de capacidade da memória de trabalho) pode induzir uma relação tradutória L2-LM estabelecida puramente no nivel das formas lingüísticas superficialmente assemelhadas. A equivalência inadequada estabelecida assim se materializa no texto-meta como interferência da L2 sobre a LM.

Assim, o automatismo da decodificação induziria a uma passagem incompleta pelo processo de compreensão, de uma não realização autêntica desse processo no módulo central, devido a tendências cognitivas que podem afetar também sujeitos proficientes na L2, enquanto que, no caso do fenômeno de interferência pelo uso heurístico da LM para compreensão da L2, mais típico da pouca proficiência na L2, a interferência aparece na produção como efeito de um empréstimo mal sucedido dentro do processo de compreensão.

Segundo proposta de Presas (2000), um caminho para a redução de interferência em tradução em bilingües proficientes seria treinar a separação entre conteúdo mental e forma gráfica ou sonora das estruturas lingüísticas, de modo, inclusive, a favorecer o processamento de cada uma das linguas em estruturas de memória conceituais separadas, cada uma delas ajustada às peculiaridades de uma das línguas em questão.

Essa proposta poderia ser formulada em termos da semântica de frames \& scenes de Fillmore, dizendo que a habilidade de lidar separadamente com as formas e estruturas lingüisticas (frames) de cada um dos idiomas envolvidos na tradução, servindo-se de dois sistemas de representação conceitual (scenes) diferenciados é, do ponto de vista da competência bilingüe, importante diferencial do tradutor competente (Snell-Hornby: 1988).

Permitiria ainda um paralelo com a proposta da "desverbalização", de Seleskovitch (1968 apud Hurtado, 2001: 324). Haveria uma fase essencial no processamento competente da 
tradução, na qual o tradutor "esquece" a cobertura lingüística e centra-se no sentido.

No caso de línguas tipologicamente próximas, talvez seja ainda mais necessário, então, desenvolver a atenção e os procedimentos de revisão para compensar automatismos do sistema decodificador de entrada, garantindo a parte principal do processo de compreensão, realizada no módulo central do cérebro e relacionada às estruturas conceituais.

Fechamos este subitem sustentando que, para construir as relações frame-frame adequadas na tradução interlingüística, seja entre linguas mais distantes ou mais próximas, é necessário um domínio refinado dos sistemas lingüísticos complexos dos dois idiomas colocados em relação de tradução, e seria desejável um treinamento específico em tradução.

\subsection{Interferência no léxico e interferência na sintaxe: análise de casos}

Finalizaremos com a análise de dois casos de interferência em tradução no par português-espanhol para considerar as duas hipóteses seguintes, derivadas do que foi exposto. Em tradução (1) o aparecimento de elementos da L2 na produção em LM parece derivar sempre de problemas no processo de recepção do texto em L2, mas esses problemas podem ser de naturezas diferentes; (2) há maiores probabilidades de interferências sintáticas do que lexicais.

No primeiro caso analisado, a interferência da LM na compreensão da L2 se manifestou num decalque inadequado, por alunos brasileiros de níveis iniciais de estudo de espanhol como língua estrangeira (E/LE), do falso cognato mariposa - "mariposa".

A opção preferencial de tradução ao PB da palavra espanhola mariposa é "borboleta" (inseto diurno). O que se designaria em PB pela palavra "mariposa" (inseto noturno) seria designado em espanhol por mariposa nocturna ou polilla.

Vinte e quatro estudantes de E/LE de nível básico traduziram um conto em que aparecia algumas vezes a palavra espanhola mariposa. Havia um cotexto que poderia ajudar a inferir 
que o bicho do conto não era a "mariposa" do PB. O conto fala de una enorme mariposa de todos colores ("uma enorme borboleta colorida"). Se as "mariposas" (insetos noturnos) também podem ter cores vivas, não é essa sua imagem prototípica. Tal imagem prototípica exclui o "ser colorida", tipicamente associado com o inseto "borboleta". O conto infantil ainda apresenta o contexto de um vôo diurno no jardim e uma apreciação positiva da beleza do inseto, fatores que poderiam servir como fortes indicios para excluir a possibilidade da equivalência mariposa - "mariposa".

As hipóteses teóricas vistas sobre estruturação da experiência na memória permitiriam supor que a presença, no cotexto do conto traduzido pelos estudantes, dos componentes de sentido "colorida", "diurna" e "bonita" deveria ativar uma rede associativa que enfraquecesse a hipótese de tradução "mariposa" para o inseto e apontasse na direção de "borboleta". Havendo um processamento atento do sentido global do texto, operando no nível das representações mentais, especialmente no âmbito da visualização de uma cena, tal rede de associações deveria ajudar um falante do português a selecionar o TC "borboleta" e, conseqüentemente, a palavra a ele associada, ao traduzir para sua LM. Mas, para isso, a atenção dirigida a informações contextuais-cotextuais deveria prevalecer sobre a semelhança gráfica entre mariposa e "mariposa".

Em nossos dados, embora dezessete sujeitos (70,83\%) não tenham caído na armadilha do falso cognato (contando que dois desses dezessete tinham proficiência suficiente em espanhol para já conhecer o significado de mariposa), uma porcentagem alta de sujeitos não se mostrou sensível a esses indícios contextuais (quase $30 \%$ ).

Por outro lado, a sensibilidade a esse falso cognato lexical em contexto se mostrou maior do que a sensibilidade a uma diferença sintática. No mesmo conto infantil de Walsh (1966), na frase inicial "ésta es la historia de una princesa, su papá, una mariposa y el principe Kinoto Fukasuka”, há elipses da preposição de antes dos três SN enumerados depois do fragmento "ésta es la historia de". Em PB, não retomar a preposição "de" antes do sintagma introduzido por determinante ("o príncipe Kinoto 
Fukassuka") e formular "esta é a história de uma princesa [...] e o príncipe Kinoto Fukassuka" soa estranho e não é gramatical. No entanto, quase $100 \%$ dos estudantes fizeram um decalque sintático neste fragmento. Num experimento posterior, isso aconteceu também com bilíngües proficientes.

Tais dados sugerem uma diferença significativa entre a capacidade de fixar a atenção consciente nas diferenças léxicas ou nas diferenças sintáticas entre L2 e LM. Se é assim, haveria maior tendência a interferências estruturais do que a interferências lexicais.

Que se faça mais automaticamente uma associação direta de estrutura lingüística da L2 a estrutura lingüística da LM sem mediação de representação mental no caso das estruturas sintáticas poderia ser explicado pela natureza mais abstrata da estrutura sintática, mais dificilmente associável à visualização ou a outros tipos de percepção sensorial (a representações mentais derivadas de percepções sensoriais do mundo).

Na presença de estruturas relacionais mais abstratas (como as sintáticas), parece maior a tendência a estabelecer uma correlação automática de forma lingüística com forma lingüística semelhante, sem ativação das redes de memória conceituais, nas quais se realiza uma importante etapa do processamento dos sentidos.

\section{Conclusões: aproximação à especificidade do português-espanhol em tradução}

Segundo as considerações anteriores, as relações entre o português e o espanhol se caracterizam (1) por uma proximidade mais superficial (plano do significante no nível do léxico) do que real; (2) por uma distância lexical (maior transparência) diferente da distância sintática e discursiva (divergência em importantes pontos específicos).

Essa combinação gera um descompasso importante entre a distância percebida e a distância real. Isso favorece que o aprendiz se arrisque mais a valer-se de empréstimos da LM para produzir enunciados na L2 e para interpretar textos na L2. 
A percepção de uma proximidade maior do que a realmente existente tem como conseqüência psiquico-social a sensação de uma "competência instantânea"17 para desempenhar-se na outra lingua, inclusive para traduzir de uma a outra, o que gera maior grau de intrusão profissional (de apredizes de L2 entrando prematuramente no mercado, ou de indivíduos não qualificados para trabalhar com esse par específico) e maior menosprezo do profissional bem qualificado. Como conseqüência cognitiva, o alto grau de proximidade percebida, induzida pela semelhança etimológica de bases lexicais, pode favorecer o acionamento dos automatismos próprios do sistema decodificador da LM, transferidos para a L2 sem passagem intermediária por processamento no sistema central.

Dado o descompasso entre a distância percebida e a distância real, o grau de interferência entre essas línguas medianamente próximas se potencializa, e aumenta a necessidade de um treinamento contrastivo mais ostensivo nos niveis sintático, discursivo e cultural, ${ }^{18}$ e de maior atenção consciente para desmobilizar a tendência a processamentos automáticos que levam a transpor diretamente estrutura lingüística a estrutura lingüística, tomando por unidade a palavra isolada, sem processamento intermediário no nivel das representações conceituais nem em niveis mais complexos de textualização. A necessidade especial de atenção contrastiva no nivvel sintático parece reforçada pela tendência a que falsas semelhanças sintáticas passem mais despercebidas do que as falsas semelhanças lexicais.

Em resumo, semelhanças superficiais entre LM e L2 tendem a favorecer processamentos lingüísticos automáticos, que produzem interferência em tradução. O trabalho sobre habilidades e estratégias que desmobilizem e/ou compensem a tendência cognitiva natural de decodificação automática pode ser espe-

\footnotetext{
17 Novamente tomo emprestada formulação escutada da Dra. María Teresa Celada.

18 Que trabalhe também sobre principios básicos de tradução como as equivalências em diferentes estratos lingüísticos e sua possivel hierarquização segundo diferentes propósitos. Temos dados de estruturas sintáticas decalcadas em tradução pela crença de que alterar demasiado a sintaxe poderia ser uma "infidelidade".
} 
cialmente necessário no trabalho com línguas medianamente próximas, como é o caso do par português-espanhol.

\section{Referências bibliográficas}

AUBERT, F. H. (1998) "Modalidades de tradução: teoria e resultados". TradTerm 5 (1). São Paulo: Humanitas/CITRAT, p. 99-128.

BROWN, G. \& YULE, G. (1983 [1993]) Análisis del discurso. Madri: Visor.

BRUNO, F. A. T. C. (2001) A compreensão da impersonalidad em espanhol por estudantes brasileiros. Dissertação de mestrado. São Paulo: FFLCH-USP.

CELADA, M. T. (1999) "Um equívoco histórico". In: INDURSCY, F. \& FERREIRA, M. C. L. Os múltiplos territórios da Análise do Discurso. Porto Alegre: Sagra Luzzatto, p. 301-302.

; GONZÁLEZ, N. T. M. (2000) "Los estudios de lengua española en Brasil”. Anuario Brasileño de Estudios Hispánicos 10, Suplemento, p. 35-55.

CINTRÃO, H. P. (2004) "Traduzindo formas de tratamento do espanhol peninsular ao português de São Paulo". In: FANJUL, A. P.; GONZÁlEZ, M. M. \& OlMOS, A. C. Hispanismo 2002. Vol I. São Paulo: Humanitas, p. 199-210.

CORDER, S. P. (1983) "A role for the mother tongue". In: GASS, S. \& SELINKER, L. (ed.). Language Transfer in Language Learning. Rowley, Mass.: Newbury, p. 85-97.

CORRÊA, R. H. M. A. (2000) "Cálculo do distanciamento/proximidade tradutórios”. In: DURÃO, A. B. A. B. \& ANDRADE, O. G. (org.). Anais das II Jornadas de Estudos Hispânicos. Londrina: Universidade Estadual de Londrina, p. 44-54.

DURÃO, A. B. A. B. (2002) “Por detrás de la transparencia existe una opacidad! La lectura por estudiantes brasileños de textos redactados en español". Anuario Brasileño de Estudios Hispánicos 12, p. 13-28. ECO, U. (1997) Kant e l'ornitorinco. Milão: Bompiani. [apud Osimo 2000] ERES FERNÁNDEZ, I. M. G. (1995) “¿Qué español enseñamos? ¿Qué español hablamos?” In: Actas del IV Seminario de Dificultades Específicas para la Enseñanza del Español a Lusohablantes. São Paulo: Embajada de España, p. 175-178. [apud Durão 2002]

TRadTerm, 12, 2006, p. 69-104 
ERES FERNÁNDEZ, I. M. G.; FLAVIÁN, E.; SACRISTÁN MARTÍN, M. P.; RODRÍGUEZ MONZÚ, M. T. (s/d): "A compreensão espontânea do Português e do Castelhano por sujeitos universitários hispano e lusoparlantes respectivamente". São Paulo [mimeo].

FILLMORE, C. J. (1977) “Scenes-and-frames semantics". In: ZAMPOLLI, A. (ed.): Linguistic Structures Processing. Amsterdam: N. Holland, p. 55-81. [apud Snell-Hornby 1988]

GARCÍA-MEDALL, J. (2000) “Traducción español-portugués: lagunas y perspectivas”. In: DURÃO, A. B. A. B. \& ANDRADE, O. G. (org.): Anais das II Jornadas de Estudos Hispânicos. Londrina: Universidade Estadual de Londrina, p. 3-31.

GONZÁLEZ, N. T. M. \& KULIKOWSKI, M. Z. M. (1999) “Español para brasileños. Sobre por dónde determinar la justa medida de una cercanía”. Anuario Brasileño de Estudios Hispánicos 9, p. 11-19.

GONZÁLEZ NIETO, L. (2001) Teoría lingüística y enseñanza de la lengua. Madri: Cátedra.

HURTADO ALBIR, A. (2005) "A aquisição da competência tradutória: aspectos teóricos e didáticos”. In: PAGANO, A.; MAGALHÃES, C. \& ALVES, F.: Competência em tradução. Cognição e discurso. Belo Horizonte: Editora da UFMG, p. 17-57.

JACOBI, C. C. B. de (2002) "Computadores, corpora y la enseñanza de español en cursos de letras". Anuario Brasileño de Estudios Hispánicos 12, p. 29-44.

KUSSMAUL, P. (2004) “Translation through visualization". < http:// www.hf.uio.no/ilos/ forskning/forskningsprosjekter/expertise/ workshops/marrakech/index.html>

MACKEY, W. F. (1970) “The description of biligualism”. In: FISHMAN, J. A. (ed.): Reading in the Sociology of Language. The Hague: Mouton, p. 554-584. [apud Presas 2000]

OSIMO, B. (2001) “O processo de tradução". In: Curso de tradução. $<$ http: / /www.logos.it/pls/dictionary/linguistic_resources. traduzione_bp?lang=b

PACTE (2001) "La competencia traductora y su adquisición". Quaderns 6, p. 39-45.

PRESAS, M. (2000) "Bilingual Competence and Translation Competence”. In: SCHÄFFNER, C. \& ADAB, B. (eds.). Developing Translation Competence. Amsterdam: John Benjamins, p. 17-31. 
RICHMAN, S. H. (1965) A comparative study of Spanish and Portuguese. Department of Romance Languages, University of Pensylvania, Ph. D. Thesis. [apud Durão 2002]

RINGBON, H. (1992) "On L1 transfer in L2 comprehension and L2 production". Language Learning 42 (1). [apud Durão 2002]

SÉGUINOT, C. (1990) "Interpreting errors in translation". Meta 35 (1), p. 68-73.

SNELL-HORNBY, M. (1988 [1999]) Estudios de traducción: hacia una perspectiva integradora. Ana Sofia Ramirez (trad.). Salamanca: Almar. SPERBER, D. \& WILSON, D. (1986 [1994]) La relevancia. Madri: Visor. WALSH, M. E. (1966 [2000]) "Historia de una Princesa". In: Cuentopos de Gulubú. Buenos Aires: Alfaguara, p. 19-23.

YOKOTA, R. (2001) A marcação do caso acusativo na interlíngua de brasileiros que estudam o espanhol. Dissertação de mestrado inédita. São Paulo: FFLCH-USP. 